\title{
1. Stumbling into action research
}

My research agenda is often to evaluate work by fraud examiners when there is a suspicion of financial crime by white-collar offenders. Two whistleblowers in a municipality in Norway had reported suspicions of fraud and corruption, which resulted in internal investigations in the municipality by external fraud examiners from global auditing firm BDO and local law firm Hjort. As the case developed, I established contact with the whistleblowers as my key informants. My research perspective developed into the role of whistleblowers in detecting and revealing white-collar crime. Both whistleblowers perceived retaliation from the chief executive in the municipality, which caused me concern. Journalists interviewed me in the local media, and I wrote articles in their newspapers. As the situation deteriorated further for the whistleblowers, I went to the local police and reported the chief executive for retaliation against whistleblowers. This chapter thus presents the background for my stumbling into action research, as the media coverage and the police report might have influenced the sequence of events in the municipality.

My research agenda is often concerned with the evaluation of investigation reports by fraud examiners when there is a suspicion of financial crime by white-collar offenders. In the current case, neither fraud examiners from global auditing firm BDO (2016) nor fraud examiners from local law firm Hjort (2018) were able to reconstruct events related to the suspicions of fraud and corruption. Two employees were the sources of information concerning fraud suspicions, acting as whistleblowers. After the failed fraud examinations by BDO (2016) and Hjort (2018), the two employees perceived retaliation from the chief executive. As a researcher, I had already established contact with the whistleblowers and their cooperation, since whistleblowers are a key source of information when there is a suspicion of white-collar crime. Local media had covered the fraud examination case for several years (e.g., Berg, 2016, 2018; Karlsen, 2018a), and I was interviewed several times to comment on the white-collar crime case (e.g., Berg, 2017b). I also wrote several articles in the local media where I expressed my opinions. I felt sorry for the two whistleblowers, and I reported the chief executive to the police in February 2018.

This chapter presents the background for my action research in terms of failing fraud examinations and the mistreatment of whistleblowers. My media presence as well as police reporting might have influenced the situation and developments in the whistleblowers' organization and of the whistleblowers 
themselves. The chapter starts by presenting the whistleblowing case and the fraud examination caused by the whistleblowers. Next, my stumbling into action research is introduced, linked to a presentation of criteria for professional action research. Finally, I discuss my reactions with criteria to determine how my approach developed as I stumbled into action research.

\section{THE WHISTLEBLOWING CASE}

The intentions of individuals to report signals of misconduct and crime are at the center of the theory of whistleblowing (Keil et al., 2010). Whistleblowing is the disclosure by an organizational member of deviant practices to someone who can do something about it. Whistleblowing intentions are higher when there is a high chance that there is a crime signal. If the signal is weak and confused by noise, whistleblowing intentions are likely to deteriorate as the potential whistleblower considers the risk for him or her (Brown et al., 2016). It is convenient for an offender to know that even though others in the organization may develop suspicions, they will not notify others about what they have observed. This may be because they are not sure if something wrong has occurred, they are not sure who to notify, or they are not sure if any whistleblowing may have consequences for themselves in the form of reprisals. That is why many people are reluctant to report their suspicions of misconduct and crime, even when they feel quite certain that something wrong has happened. Many who have cast light on critical conditions have experienced unwillingness among recipients to look into the matter and to consider their reports, and they have been isolated and considered less attractive in the labor market afterwards. Reprisals and retaliation against a whistleblower represent an outcome of a conflict between an organization and its employee, in which members of the organization attempt to control the employee by threatening to take, or actually taking, an action that is detrimental to the well-being of the employee (Regh et al., 2008).

Helge Moen was chief financial officer (CFO) in Grimstad municipality. He blew the whistle on corruption in public procurement in the municipality in the spring of 2016. He reported his concern first to the chief executive and later to the chairperson of the control committee in the municipality. There was no reaction, and he got frustrated. He then was on sick leave for half a year before returning to work. After working for about 40 days, he reluctantly felt he had to move because of the tense situation in the working environment. The retribution against Moen took the form of an investigation that the chief executive engaged a consultancy firm to conduct. Investigators from the consulting firm interviewed Moen on Thursday, March 1, 2018. Among other things, the consultants confronted him with his complaints about the management. He only had access to read the accusations on a PC 
during the meeting with the consultants, and he had to make notes as quickly as possible while being interviewed. Then the consultants invited him to contradiction in terms of comments to all accusations after the meeting based on his own notes that were certainly lacking completeness and detail. The right to contradiction is a legal term that defines a fundamental principle in the civil process that the court should not settle a case without the parties having been able to respond completely to the counterparty's representation of the case. By a factual survey or a fraud investigation, the principle of contradiction contends that an affected person must have a complete opportunity to comment. The person affected by a decision in the investigation must have the opportunity to promote his or her view on the matter. The question is whether you are able to promote your view in the matter if you only see something on a PC while in a meeting.

Moen had not complained about the management. He had in meetings and by email requested that the professional and personal conditions and circumstances reflect his position as the CFO, and he asked for organizational adjustments so that he could return to work. The chief executive had been trying to relocate Moen since July 2017. The chief executive had attempted to degrade him from the CFO position to staff member in the analysis and development department. On January 23, 2018, Moen perceived that the chief executive was forcing him to move physically out of the finance department into the analysis department, and so he did. One of the allegations was that staff in the finance department had presumably pointed out that Helge Moen, despite being chief financial officer, had shown no willingness to participate in the municipality's enterprise resource planning (ERP) project in the second half of 2016. This was in fact a decision made by a municipal manager, not by Moen himself. Another allegation was that the municipal manager considered Moen's competence not to be the best in the ERP area of accounting systems. A third allegation concerns poor information flow in the finance department. Moen agrees. However, he has participated in very few meetings of the chief executive's management team or of the strategic management team. Management meetings disappeared from schedules several times.

Moen was unable to attend the finance department's seminar on the working environment on November 15, 2017. He had specifically asked to participate. In retrospect, Moen became aware that management presumably had learned of significant alleged workplace challenges in the finance department. While Moen was on sick leave, the chief executive attended a meeting with staff in the finance department on August 18, 2017. At the meeting, the chief executive asked questions about Moen, and wrote in the minutes from the meeting; "On a scale from 0 to 10 we consider Helge Moen's contribution to be 3". In her minutes from the meeting, she also wrote, "Helge Moen's 
role is more like a finance director in a big municipality ... and even as a professional economist, he made little effort to get into the new system", and that "there is a big gap between how he fulfills the role in practice and the image created through the media". These comments conveyed the chief executive's role as head of the meeting and referee, demonstrating that the whistleblower was exposed to negative comments in the organization. Another similar meeting took place on January 16, 2018, where the written minutes of the meeting state that "staff in the finance department find that Moen as the $\mathrm{CFO}$ has been released into the organization in 'free move' style". Furthermore, the written minutes say that, "the CFO is out to make trouble", that "they are uncertain about the CFO's motives", that "getting the CFO to take on a concrete task is like grabbing a pack of jelly", and that he "is a plug in the system and places sticks in the wheels". At that time, the consultants expected to deliver their report from the so-called facts inquiry to the chief executive before Easter in 2018. Moen expected the chief executive to use the report to remove him from his position as the CFO in the municipality, thus preventing him from participating in meetings, and exposing him to expulsion and harassment (Berg, 2018).

The chief executive allegedly monitored Moen's calendar. As the financial manager of the municipality, he perceived that the chief executive prohibited him from talking to the auditor. Moen also perceived that he could not talk to his own employees in the finance department.

Helge Moen was one of the whistleblowers. The other whistleblower was Ragnar Holvik. Independently of Moen, Holvik blew the whistle on corruption in public procurement at about the same time in the spring of 2016. Moen and Holvik did not know about each other's notifications. The contents of Holvik's warning concerned the assistant municipal manager for health and care services, who had favored her sister-in-law to be the provider of health services without a proper procurement procedure and process. The recipients of Holvik's warning were the chief executive and a municipal manager, as well as all members of the municipal council. The first reaction to his warning was ignorance and rejection. Next, nobody acted upon the whistleblowing letter. Then, Holvik experienced public harassment by politicians who claimed he was wrong. Then, after a fraud examination conducted by global auditing firm BDO (2016), the conclusion was that illegal procurements of healthcare services had indeed occurred. However, the ruling parties in the municipality decided not to report the alleged crime cases to the police.

After the BDO (2016) report, both political bodies and the management of Grimstad municipality had to acknowledge Moen as well as Holvik as being whistleblowers.

Then the perceived retaliation started, and Holvik too became sick and was on sick leave for almost a year. Before returning to his position as a 
chief advisor to the chief executive, Holvik lost key assignments. The mayor criticized Holvik publicly. The mayor thus broke the rule of confidentiality concerning employees in the municipality. Holvik had to hire an attorney to defend his case, and the attorney launched a claim on behalf of Holvik for retaliation and harassment.

When Holvik returned to work in January 2018, he felt immediately isolated by being assigned an office far away from the town hall where all his colleagues had their offices. He perceived that he had been deprived of most of his duties. Holvik, still formally a chief advisor to the chief executive, was no longer attending meetings within his own field of work, because the chief executive did not allow him to do so. Holvik, together with his attorney, documented a series of retaliation incidents in the form of exclusion and harassment.

The chief executive did not intervene to defend Holvik against a politician who claimed in a newspaper article that Holvik was an employment case in the municipality. The chief executive was silent in the next city council meeting. When a different politician asked whether Holvik was an employment case towards the end of the meeting, the chief executive had to confirm that there was no such case against Holvik. Holvik felt that his superior, the chief executive, let politicians tell all kinds of stories about him in public.

In the winter of 2017/2018, the retaliation processes undertaken against Holvik and Moen were very different. The charges against Holvik took place mainly in public spaces, such as the media-communicated political meetings in the town hall. Retaliation against Moen occurred mainly in the town hall with easily identifiable actors. While a large gallery of visible and invisible actors in the administration, politics and the community were active in discussing Holvik's whistleblowing and behavior afterwards, Moen's case entered into an acute phase with the chief executive as the main identifiable actor. Holvik's case was a political issue between the ruling parties and the opposition parties - for example, as it related to the repayment of attorney expenditures - more so than Moen's case. In addition, Holvik experienced all kinds of messages and opinions on social media on a daily basis.

The implementation of the city council's decision regarding compensation of Holvik's attorney expenditures assumed that he refrained from suing the municipality for retaliation. He perceived this decision as another act of retaliation from his employer. In addition, he also perceived that the lack of an invitation to a seminar for all the leaders of the municipality was an act of retaliation (Karlsen, 2018a).

At the time of writing this case study in March 2018, both Moen and Holvik were subject to retaliation on a more or less continuous basis. 


\section{THE FRAUD EXAMINATIONS}

Fraud examiners from global auditing firms and local law firms are in the business of reconstructing past events and sequences of events when there is a suspicion of misconduct and crime in client organizations. Fraud examiners' ability to complete their investigations successfully is dependent both on their skills and on the situation they are facing in the client organizations. In our case, the client organization is a municipality in Norway. The municipality suffered from institutional deterioration, as researchers have discussed in institutional theory (Itzkovich and Heilbrunn, 2016). Executives in the municipality remembered little or nothing of negative events, and documents and emails regarding the events were all gone. Institutional deterioration thus opened up into a blame game, where external attribution for negative events was possible (Pillay and Kluvers, 2014).

First, the control committee hired fraud examiners from global auditing firm BDO (2016) to investigate the suspicion of financial crime in healthcare procurements in the municipality. Two years later, the control committee hired fraud examiners from local law firm Hjort (2018) to investigate the same suspicion of misconduct and crime among executives in the municipality. None of the examiners was able to reconstruct the past or the sequence of events.

In connection with their mission, fraud examiners from BDO (2016) stated that it was difficult to find written documentation and launched the possibility of reviewing electronically stored documentation, such as emails from some employees in the municipality, as fraud examiners assumed that this would illuminate and clarify further facts in the case. The municipality of Grimstad decided that an inquiry among employees in Grimstad municipality who had been dealing with the "purchasing case" should take place. On June 29, 2017, the control committee of Grimstad municipality sent an invitation to tender for the conduct of the analysis to five law firms. On July 12, 2017, the Norwegian data protection agency expressed concern regarding the tender. They contested the control committee's ability and legitimacy to conduct such an inspection. It turned out that the data protection agency was wrong, and they had to withdraw from their warning of banning the investigation. Then the same firms received new invitations to submit offers by email by October 6, 2017. Law firm Hjort submitted a timely offer, and it was announced by email on November 3, 2017 that Hjort was chosen to carry out the fraud examination. From the tender invitation, the following description of the mandated assignment presented itself to potential fraud examiners:

The municipality of Grimstad wishes to carry out an analysis of employees' emails in the municipality to try to further elucidate the issues in the BDO report and how Farm in Action got its first agreement with Grimstad municipality. BDO has 
previously submitted a report. The municipal council wishes a written report / memorandum on the findings of the examination which will be presented to the control committee and the municipal council. The report / memorandum shall address information provided in emails and assess whether this further elucidates the issues based on previous information given in the case. Previous information refers to previous reports and information provided by the administration along the way.

Mirror copies of current employees' email accounts and private digital areas have been made in early October 2016.

There are basically two specified employees whose email accounts will be examined. Should information in this analysis indicate that other persons have been central to the procurements then the assignment could be expanded to include those persons.

The two specified employees were the municipal manager and the deputy/ assistant municipal manager for health and care. Fraud examiners from law firm Hjort (2018) were required to review all contents of their email accounts as well as the user areas of these two persons. Start-up meetings took place with the supervisory board as well as the chief executive who had replaced the previous chief executive in 2016. At the meetings, they discussed the process and schedule, and many board members used the opportunity to ask questions. Hjort (2018) claim in their report that there was a good dialogue with the two primarily concerned ("the affected parties"), as well as their lawyers. There was a written account of how examiners would conduct data processing and analysis, as well as about deletion routines, when and how the examination would take place, the right to be present and the right to bring a lawyer or other counselor/trusted representative. Furthermore, there was a written account about how documents were identified (use of keywords, etc.), how extracted documentation was used, and protocoling, including any disagreements as to the opening of certain documents. A telephone/video meeting also took place with the two affected parties, in which their attorneys assisted them. Both agreed that the examination found sufficient legitimacy without being present. Both also provided input to possible sources and procedures for obtaining additional information.

Hjort (2018) considered whether there were grounds for recommending that others become subject to the inquiry in addition to the two individuals that the examination initially included, but the fraud examiners found no reason to recommend this based on the quality of the data collected (as discussed below). As the fraud examiners saw it, it was not appropriate to expand the circle of people because the poor data quality was unlikely to provide more information.

Since Hjort (2018) is a law firm, they recruited technical assistance from a computer forensics company. Examiners claimed they used digital forensics methods and tools for indexing and searching data. The basis for the analysis was the previously secured server data from Grimstad munici- 
pality's operating supplier IKT Agder. Reviewed data consisted of file data from the Grimstad municipality's file server, consisting of a common area for all users and the home user areas of the affected parties. In addition, the reviewed material included a complete database of the mail server, from which forensics had taken the outgoing mail accounts of the affected parties. All the data were a result of IKT Agder's security policies and their conservation of server data in October 2016. Examiners indexed and searched these data with defined keywords or combinations of words and terms. Examiners formulated keywords based on information received in the case, including the BDO report and information from the principal, stakeholders and others who had contacted Hjort. The affected parties received a list of keywords and had the opportunity to add words and phrases. In the end, 68 keywords were entered into a digital search engine. The digital forensic firm presented all their findings from the data to Hjort on a data platform for a qualified review and assessment of information. They created an audit log for all files that they had opened for access. Information that examiners considered relevant received a flag in the data platform to denote it as "relevant", and was copied to an external storage device for analysis and reporting. Then they opened and retrieved all relevant documents. The affected parties received a report from the fraud examiners regarding documents that they had obtained from the affected parties' respective email accounts.

With the assistance of digital forensics experts, Hjort (2018) reviewed data secured by IKT Agder based on recommendations from BDO (2016). The review showed that the data were insufficient to answer the investigation's mandate. The IT manager had only secured data stored on servers, and missing backup routines made it impossible for examiners to access older data. The IT manager had not secured data on PCs and other media. Hjort (2018) claims in their report that they were unable to retrieve and revitalize deleted data. Digital forensic experts should be able to recover deleted data from computer systems, so there is a question of whether the fraud examiners had hired real experts and whether they had asked these experts relevant questions to retrieve and revitalize the deleted data.

Hjort (2018) seems to have followed a different path by blaming IKT Agder for not having properly secured the necessary data for email analysis. The fraud examiners claim that BDO (2016) had explicitly asked IKT Agder not to delete any emails as long as investigations were still ongoing. IKT Agder had received a request to secure the email accounts of employees in the procurement department, housing service, and management department, as well as those of finance executives, the chief executive, purchasing managers and municipal managers. Furthermore, BDO had also asked for access to backups from the document management system at four specific points in time - 
September 21, 2016, April 30, 2016, December 31, 2015 and January 1, 2012 or from as close as possible to these dates. Similarly, examiners had requested access to backups from file servers and data areas used by the municipality. A subsequent email exchange from September 22 and September 27, 2016 raised issues that nobody had clarified. By means of a double message, sent on October 10 and October 14, 2016, BDO sent a list of users in the municipality of Grimstad that were of special interest. Examiners asked IKT Agder to secure all available data related to these persons.

\section{ACTION RESEARCH CRITERIA}

Action research is an approach to research rather than a specific method of data collection, underpinned by cycles of planning, acting, observing, reflecting and re-planning. Action research has the metaphor of a spiral because it is a continuous and iterative process (Walsh et al., 2014). In the current study, the researcher reacted to and acted upon developments in the organization in question.

Action research is a family of practices of living inquiry that aims, in a variety of ways, to link practice and ideas in the service of human flourishing (Drake, 2014). Action research is not a method, but an orientation to inquiry, with many schools, theories and practices. As such, action research must be prepared as if it were an insurgent campaign, with a strategic view of the field of power it enters, and with the utmost care for those most vulnerable to retaliation (Martinez, 2017).

Action research, as repeated by Brydon-Miller et al. (2003), is a participatory, democratic process concerned with developing practical knowledge in the pursuit of worthwhile human purposes, grounded in a participatory worldview, which we believe is emerging at this historical moment. It seeks to bring together action and reflection, theory and practice, in participation with others, in the pursuit of practical solutions to issues of pressing concern to people, and more generally the flourishing of individual persons and their communities. The following are the most prevalent action strategies suggested by Argyris (1995): (i) advocate your position, (ii) evaluate the thoughts and actions of others (and your own thoughts and actions), and (iii) attribute causes to whatever you are trying to understand. This is in line with Argyris' Theory-in-Use model (Model 1) that has four governing values: (i) achieve your intended purpose, (ii) maximize winning and minimize losing, (iii) suppress negative feelings, and (iv) behave according to what you consider rational.

Action research can have five stages: (i) diagnosing, (ii) action planning, (iii) action taking, (iv) evaluating, and (v) specifying learning. The spiral metaphor refers to repeating the five stages as needed. Action research can involve 
a number of commitments to observe and problematize through practice a series of principles for conducting social inquiry (Durcikova et al., 2018).

An important decision in action research is the choice of key informants. The trigger for this research was whistleblowers as key informants who wanted to tell their stories of mistreatment and alleged retaliation. As argued by McKenna and Main (2013), the value and challenges involved in selecting and relying on key informants to represent the case cannot be overstated. Because key informants inhabit social and professional roles in communities and organizations, they can provide researchers with knowledge and inside information related to the case. The purpose is not necessarily objectivity, but a certain perspective. Key informants typically serve as gatekeepers regulating access to people and sources of information as cultural experts explaining a culture to an outsider. To fill the role of key informants, they should meet the following criteria: hold formal positions in the community, have knowledge relevant to the study, be willing to share their knowledge, communicate well, and be unbiased or able to reflect upon their own biases.

Academic integrity is important in action research. Reflection should follow action, as reflection is a response to action that has occurred. The academic integrity of action research depends both on the researcher's capability of solving pertinent problems and at the same time rigorously scrutinizing the experiences from the field engagement in order to communicate researchbased findings. This dual perspective (action and reflection) distinguishes action research from most conventional social science practices (Levin, 2012).

The essential challenge in action research is the unique combination of deep empathic and political involvement coupled with critical and reflective research, which expects the researcher to treat his or her own experiences at "arm's length" (Levin, 2012). I had deep empathetic involvement with both whistleblowers, while at the same time doing research on the suspected crime and the conducted fraud examinations.

The immediate understanding created by active involvement in the field must be subject to the critical inspection necessary for scientific reasoning. This critical examination requires stepping out of the experiential world and positioning oneself as a critical researcher. This dual role requires a combination of empathy and involvement combined with critical and analytical skills (Levin, 2012). 
Action research is an orientation to knowledge creation that arises in a context of practice and requires researchers to work with practitioners (Huang, 2010: 93-4):

Unlike conventional social science, its purpose is not primarily or solely to understand social arrangements, but also to effect desired change as a path to generating knowledge and empowering stakeholders.

Action research does bear resemblance to, and frequently draws from the methods of, qualitative research in that both are richly contextualized in the local knowledge of practitioners. However, qualitative research is research about practice, not with practitioners.

The method applied in this case study represents a variation of action research. The method might be labeled critical, provocative and confrontational action research. Critical action research can imply "getting your hands dirty" (Ram et al., 2015: 462), since it was "time to get real" (Meehan et al. 2016: 255) by challenging assumptions and thinking:

Critical management scholars claim that academic research should aim to systematically challenge assumptions and thinking.

According to Schwencke (2017: 361), critical action research is concerned with undemocratic structures in society that lead to distance and a perception of structures as frozen, that it is impossible to influence or do something about.

Provocation can be common in other contexts, such as police investigations, where the purpose is to cause reactions among suspects. The purpose of my provocations was to create reactions from persons who disliked my attention and therefore preferred not to answer my questions. There were persons who might have participated in or contributed to misconduct and crime, or participated in or contributed to concealment of misconduct and crime. Furthermore, there were persons who had handled whistleblowers and exposed them to perceived retribution. The purpose of my provocations was to cause information transfer.

Levin (2017) recommends critical confrontation combined with analytical distance in action research. Confrontation is an argumentative meeting or situation between opposing parties. I confronted key actors in the municipality with allegations concerning their involvement in illegal procurement, concealment of misconduct, as well as retribution against whistleblowers. I kept analytical distance by compiling notes in manuscript form where I reorganized observations, linked observations, and added explanations from the literature as new insights emerged. It was a social inquiry (Durcikova et al., 2018). Action and reflection followed each other (Levin, 2012). 


\section{ACTION RESEARCH DISCUSSION}

This chapter presents an action research case study. However, this action research developed very differently from other action research studies. For example, McManners (2016) reports his study as consisting of three rational and consecutive phases. The first phase was a preparatory phase that examined the situation in depth in order to be able to propose a feasible solution. The second phase involved seeking ideas from another sector with similar characteristics. Finally, the third phase consisted of engagement with stakeholders across stakeholder groups. The action research presented in this chapter occurred in a dynamic and spiraling manner as events and sequences of events occurred.

Action research can be a reflective process of progressive problem solving led by researcher(s) working with others to improve their situation. Action research involves actively participating in a changing situation, often via an existing organization, whilst simultaneously conducting research. As a researcher, I was actively participating as an advisor to both whistleblowers, while at the same time conducting research into the suspicions of white-collar crime and the evaluation of fraud examinations.

Action research in the current study challenges traditional social science by moving beyond reflective knowledge, created by outside experts sampling variables, to active moment-to-moment theorizing, data collecting and reflecting on the main topics of suspicions of white-collar crime, fraud examination failures, and the treatment of whistleblowers.

Cooperation is important to create change, but cooperation may occur with some and not with others. In the current research, in which the perspective is on the detection of potential white-collar crime and the perception of retaliation against whistleblowers, cooperation has mainly focused on the whistleblowers and neutral sources of information. People who felt threatened by my action research had the choice of remaining silent or responding to my provocations to communicate information and to express their opinions in modes of contradiction.

Action research is an interactive inquiry process that balances problem-solving actions with data-driven research to understand underlying causes. In this research, the underlying cause is a suspicion of white-collar crime, while the situation for whistleblowers is one of concern for their welfare.

Action research can balance actions taken and research reflections, or it can adjust the balance to focus on one of the perspectives more than the other perspectives. The current study progressed more from the researcher's agenda than from the participating whistleblowers. 
In action research, one seeks to develop new relationships that go beyond typical roles and power disparities (Friedman et al., 2018). The actual power relationship that emerged between the researcher and the two whistleblowers went through a number of stages over a period of more than a year. First, the whistleblowers told me their stories as though I was to defend them as their defense lawyer. A defense lawyer can be subjective and show interest in incidents that might serve as punchlines in a potential claim document and in possible court proceedings. Next, the whistleblowers understood that I had my own research agenda, and they were happy to contribute facts about their suspicions, suspects and other inside information from the organization. Finally, a mutual understanding emerged where they provided me with information, while I provided them with advice.

Action research took place through cooperation between the researcher and the concerned whistleblowers and their supporters, in order to promote emancipation and a better life (Gustavsen, 2014). This was on the positive side. The purpose on the negative side was to prevent the deterioration of their life circumstances. The current case of action research is critical, provocative and confrontational, where "getting your hands dirty" (Ram et al., 2015: 462) is a relevant characteristic, as mentioned above. Meehan et al. (2016: 255) argue that it is "time to get real" in critical action research by challenging assumptions and thinking.

My stumbling into action research to prevent further escalation of the perceived retaliation against two whistleblowers raises a number of issues. First, I am not sure what influence my actions may or may not have had. I reported the chief executive to the police in February, and this generated serious attention in the local community. Nevertheless, the chief executive hired consultants to find wrongdoings by one of the whistleblowers, resulting in his dismissal from the CFO position in June. Second, having the whistleblowers as key informants certainly made me biased and emotionally involved. While I regularly went back to my research agenda, I became almost convinced that fraud and corruption had indeed occurred. Third, politicians and others in the local community got confused about my role, as they asked whether I was a researcher or an activist. At this point, I explicitly defined my activities as action research, upon which a number of further issues arose, such as integrity, accountability, respect, justice and participation.

There are obvious learning points from my action research concerned with the role of whistleblowers in the municipality. First, I should have established contact with the chief executive to get her views. Second, I should have explained my role to the whistleblowers at the outset. Third, I should have developed a plan as my involvement increased. Finally, I should have defined for myself a clear distinction between research findings and subsequent actions. 